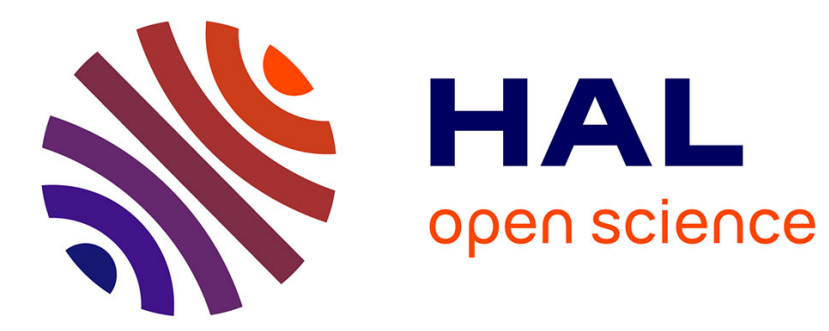

\title{
Electrochemical activation of halogen bonding
}

Claire Fave, Bernd Schöllhorn

\section{To cite this version:}

Claire Fave, Bernd Schöllhorn. Electrochemical activation of halogen bonding. Current Opinion in Electrochemistry, 2019, 15, pp.89-96. 10.1016/j.coelec.2019.04.005 . hal-02315119

\section{HAL Id: hal-02315119 \\ https://hal-univ-paris.archives-ouvertes.fr/hal-02315119}

Submitted on 14 Oct 2019

HAL is a multi-disciplinary open access archive for the deposit and dissemination of scientific research documents, whether they are published or not. The documents may come from teaching and research institutions in France or abroad, or from public or private research centers.
L'archive ouverte pluridisciplinaire HAL, est destinée au dépôt et à la diffusion de documents scientifiques de niveau recherche, publiés ou non, émanant des établissements d'enseignement et de recherche français ou étrangers, des laboratoires publics ou privés.

\section{(c)(1)}

Distributed under a Creative Commons Attribution| 4.0 International License 


\section{Electrochemical activation of halogen bonding Claire Fave and Bernd Schöllhorn}

\begin{abstract}
In the past, noncovalent interactions have been extensively studied by electrochemical methods. In this context, halogen bonding (XB) has been a long-time overlooked item in the toolbox of supramolecular chemistry. The article is treating electrochemical activation of XB in solution and at the solidliquid interface. Key principles and recent work on the use of electrochemistry as a tool for detecting and controlling $X B$ are reported. Different types of redox-switching $X B$ are identified in the context of molecular recognition and detection. First evidence for XB promoted electron transfer reactions involving the activation of covalent bonds represents a completely new and emerging domain, ripe for exploration.
\end{abstract}

\begin{abstract}
Addresses
Laboratoire d'Electrochimie Moléculaire, UMR CNRS 7591, Université Paris Diderot, Sorbonne Paris Cité, 15 Rue Jean-Antoine de Baif, F75205, Paris Cedex 13, France
\end{abstract}

Corresponding authors: Schöllhorn, Bernd (bernd.schollhorn@univparis-diderot.fr); Fave, Claire (claire.fave@univ-paris-diderot.fr)

\section{Keywords}

Halogen bonding, Noncovalent interactions, Redox switching, Molecular recognition, Molecular electrochemistry, Anion detection.

\section{Introduction}

Halogen bonding (XB), an attractive interaction between a halogen atom acting as an electrophilic species (called $\mathrm{XB}$ donor) and a Lewis base (called XB acceptor) (Figure 1), is nowadays fully recognized by the scientific community as an important noncovalent interaction and an interesting tool for applications either in crystal engineering or materials science but also for (bio)supramolecular chemistry in solution and at the liquid-solid interface. [1,2] In 2013, the term 'halogen bonding' was officially defined by International union of pure and applied chemistry (IUPAC) [3], stressing its complementarity with hydrogen bonding (HB), and is well documented in the solid state [4-9]. This is not the case for systems in homogeneous solution or at the electrode surface despite the interest of emerging applications in molecular recognition, anion sensing and transport, medicinal chemistry, and organocatalysis. [1,2], [10-12] Most published studies of XB in solution rely on spectroscopic techniques such as ultraviolet-visible (UV-vis), infrared (IR), Raman, and nuclear magnetic resonance (NMR) spectroscopy [10]. In the seventies, dielectric polarization measurements were conducted for the characterization of organohalides in organic solvents allowing for a distinction of the observed XB from other noncovalent interactions [13]. Surprisingly, and despite their low cost and relatively simple implementation, electrochemical methods remained absent until 2014 [14]. The challenge to explore the electrochemical activation of $\mathrm{XB}$ for molecular recognition in solution and in surface confined systems is, in our view, a new and attractive topic, and some questions have only recently been addressed. Tuning the strength of a redox active $\mathrm{XB}$ donor via a reversible electrochemical reaction should change its affinity toward $\mathrm{XB}$ acceptors and vice versa (Figures 1 and 3 ). Such type of redox switching is of great interest because the electrochemical probing and controlling of $\mathrm{XB}$ will help to better understand the corresponding supramolecular properties and reactivity in complex systems such as liquid electrolytes involving multiple competing noncovalent interactions. The present article reports on the most recent studies in this field.

\section{Redox switching of XB acceptors: reductive XB activation}

In aprotic solvents, quinones can be reversibly reduced in two sequential one-electron transfer (ET) steps $[15,16]$ generating the corresponding anion radical (semiquinone radical) and dianion, with a consequently significant increase of the respective Lewis base strength. The influence of HB donors and Lewis acids on the electrochemical behavior of quinones has been extensively studied in the past [17-21]. The observed shifts of the quinone reduction potentials were attributed to the stabilization of the corresponding anions because of their association with $\mathrm{HB}$ donors (in the absence of proton transfer reactions) and Lewis acids (eg. alkali and earth-alkali metal cations) [22,23]. An analogous behavior has been demonstrated recently for $p$-quinones such as tetrachloroquinone (TCQ, Figure 2) or dichlorodicyanoquinone (DDQ, Figure 2), validating for the first time the concept that the strength of XB can 


\section{A) Halogen Bonding}

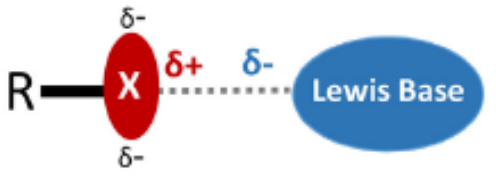

* Strong directionality (bond angles close to $180^{\circ}$ )

* Strength comparable to $\mathrm{HB}(5-180 \mathrm{~kJ} / \mathrm{mol})$

* More hydrophobic character compared to HB

$\mathrm{X}=\mathrm{I}, \mathrm{Br}, \mathrm{Cl}$

\section{B) Electrochemical Switching of XB: Activation and Detection}

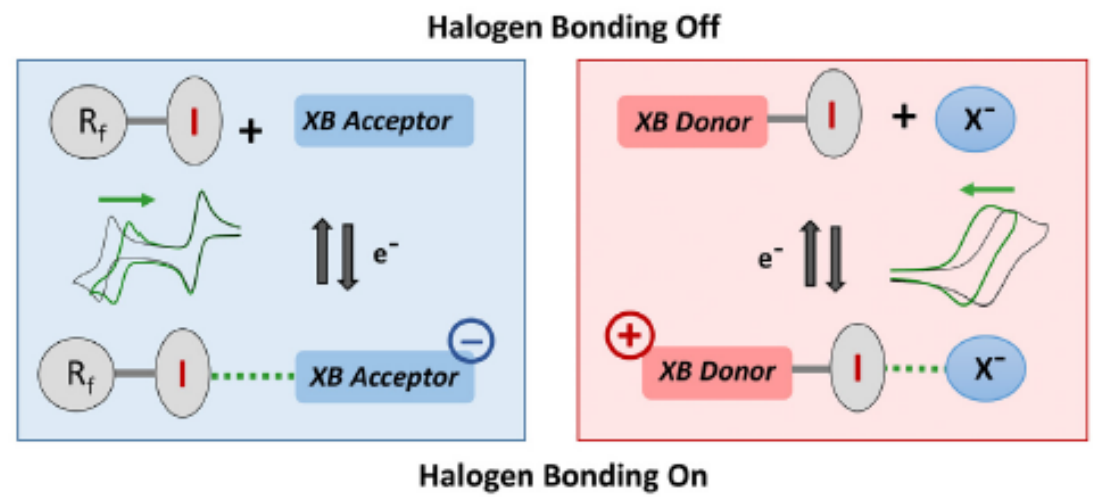

a) Schematic representation of halogen bonding. (b) Electrochemical switching of redox-active XB acceptors and XB donors in the presence of iodoperfluorocarbons and halide anions, respectively. XB, halogen bonding; $\mathrm{HB}$, hydrogen bonding.

be controlled by the redox switching of the Lewis basic $\mathrm{XB}$ acceptor (Figures 2 and 3) [14]. Cyclic voltammetry (CV) was thus identified as an analytical technique well adapted to probe and control XB interactions in liquid electrolytes. Iodo-perfluorocarbons $\left(\mathrm{I}-\mathrm{R}_{\mathrm{f}}\right)$ induced high standard potential shifts exclusively of the second TCQ reduction wave (corresponding to the TCQ dianion formation) of up to $140 \mathrm{mV}$ in polar electrolytes, such as acetonitrile containing $0.1 \mathrm{M}$ of tetrabutylammonium hexafluorophosphate $\left(\mathrm{TBAPF}_{6}\right)$ as the supporting electrolyte salt. A stoichiometry of 1:1 was deduced from Job plots, and binding enhancements (ratio of the equilibrium constants $K_{3} / K_{2}$ of the respective XB complexes, Figure 3) of up to $10^{3}$ could be determined by simulation and fitting of the voltammograms to the experimental results. Competition experiments involving two different Lewis bases (dianionic quinone and chloride) were conducted evidencing reversible equilibra between the formed $\mathrm{XB}$ complexes and allowing for the indirect determination of affinity constants between the involved nonelectroactive species (halide anions and $\mathrm{I}-\mathrm{R}_{\mathrm{f}}$ ).

\section{Redox switching of XB donors}

Two different ways to electrochemically switch XB donors have been described in recent literature (Figure 2). In the first case, the donor strength is increased upon oxidation of a neutral or cationic redox center, thus activating XB. In a second case, cationic $\mathrm{XB}$ donors are reduced involving $\mathrm{XB}$ deactivation. Both switching modes have been applied to selective anion detection, an important issue in analytical chemistry $[24,25]$.

\section{Oxidative XB activation}

Iodinated tetrathiafulvalene (TTF) and ferrocene $(\mathrm{Fc})$ derivatives have been used as redox moieties for $\mathrm{XB}$ activation upon electrochemical oxidation. In general, the XB-donor strength of organohalides increases with the size and polarizability of the halogen atom $(\mathrm{I}>\mathrm{Br}>>\mathrm{Cl}>>\mathrm{F})$ and the presence of electron withdrawing groups. Iodo-alkynes and iodoperfluorocarbons are known to be particularly strong $\mathrm{XB}$ donors. Besides these neutral compounds, more recently, it has been proven by NMR spectroscopy that cationic halogenated compounds (halo-imidazolium and triazolium derivatives) [26,27] also possess strong XBdonor properties. The use of positively charged receptors that benefit from a Coulombic attraction to anions is recognized as a promising general strategy for anion recognition. Electrochemical oxidation represents a well-adapted tool for conveniently generating positive charges in molecular systems under ambient conditions. Since 1995, electrocrystallization was used to prepare various solid-state donor-acceptor complexes based on 


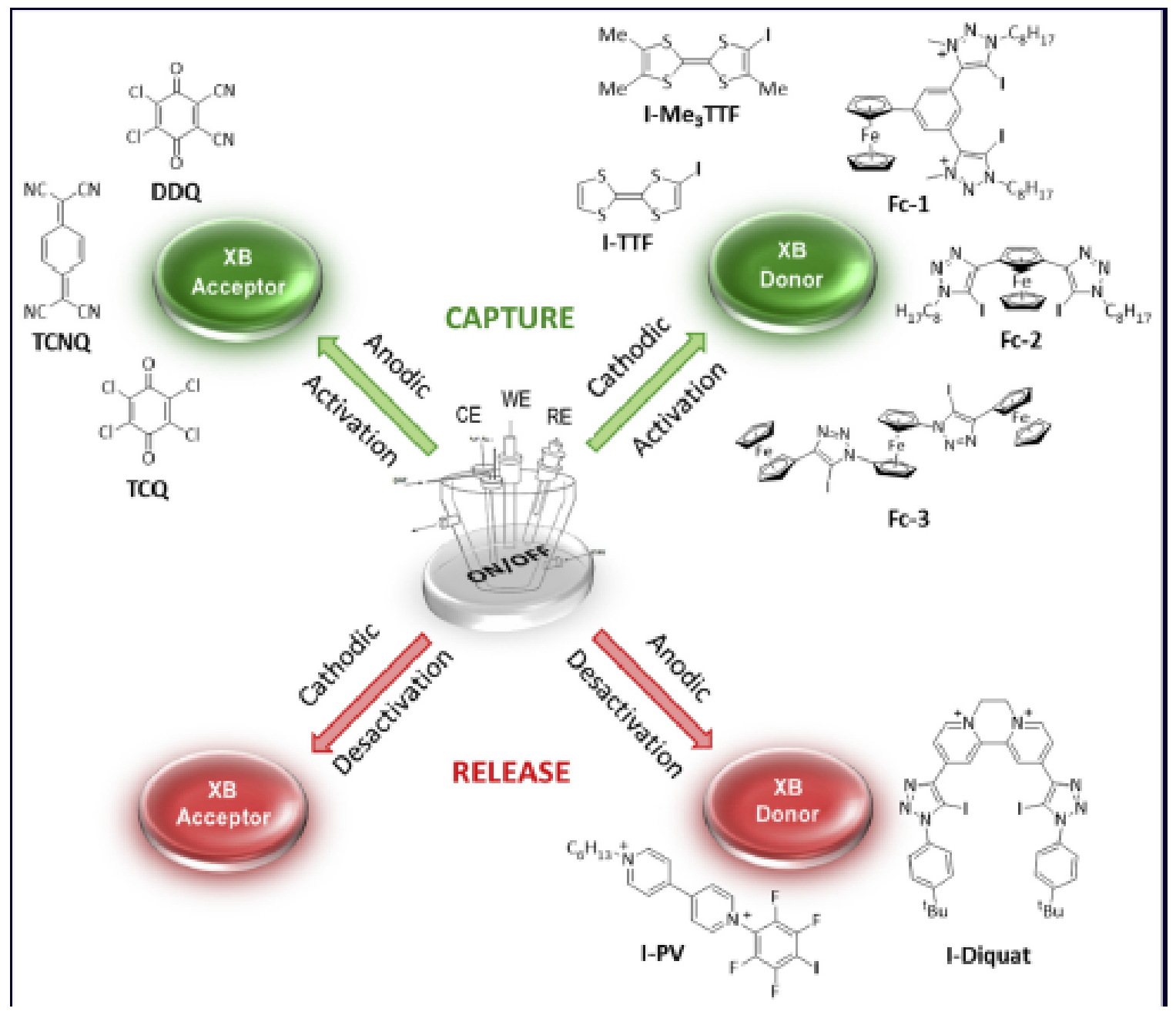

Classification of the redox probes used for electrochemical XB activation/deactivation. XB, halogen bonding; TCQ, tetrachloroquinone; TTF, tetrathiafulvalene; Fc, ferrocene; $\mathrm{DDQ}$, dichlorodicyanoquinone $\mathrm{CE}$, counter electrode; WE, working electrode; RE, reference electrode; TCNQ, tetracyanoquinone; PV, phenylviologen.

charge-assisted XB involving iodo-tetrathiafulvalene (ITTF) derivatives [28]. Recently, the XB-donor strength of iodinated TTF derivatives (I-TTF and $\mathrm{IMe}_{3}-\mathrm{TTF}$, Figures 2 and 3) has been electrochemically modulated and controlled in DMF solution [29,30]. A significant binding enhancement to $\mathrm{Cl}^{-}$upon oxidation of I-TTF ('XB OFF') to $\mathrm{I}^{-T T F}{ }^{+}$('XB ON') was observed and attributed to the strong inductive effect of the generated positive charge polarizing the C-I bond. The significant contribution of $\mathrm{XB}$ to the observed stabilization of I-TTF $^{+}$was proven, and other noncovalent interactions such as $\mathrm{HB}$ or $\pi$-anion interactions could be excluded. First spectroelectrochemical measurements in the Uv-vis range along with Time-dependent density functional theory (TD-DFT) calculations confirmed XB formation upon generation of the cation radical. Depending on the nature of the anion $\left(\mathrm{Cl}^{-}, \mathrm{Br}^{-}, \mathrm{TfO}^{-}\right)$, oxidation potential shift values in the range of $0-50 \mathrm{mV}$ have been observed and affinity constants of up to $425 \mathrm{M}^{-1}$ could be determined for the XB adducts, corresponding to a binding force of around -12 to $-15 \mathrm{~kJ} \mathrm{~mol}^{-1}$. Moreover, competition between I$\mathrm{TTF}^{1+}$ and other XB donors (iodo-perfluorocarbons) as well as HB donors (alcohols, water) for the recognition of $\mathrm{Cl}^{-}$allowed for the quantitative comparison of the relative donor strength. This competitive approach is an interesting electroanalytical tool for probing noncovalent $\mathrm{XB}$ and $\mathrm{HB}$ interactions in solution. Thanks to the second oxidation step affording, the more electrophilic dication $\mathrm{I}_{-T T F}{ }^{2+}$, it was possible to detect $\mathrm{XB}$ even in protic media (water/DMF and ethanol/DMF mixtures).

The redox properties of $\mathrm{Fc}$ have been exploited in a similar way for the electrochemical detection of anions 


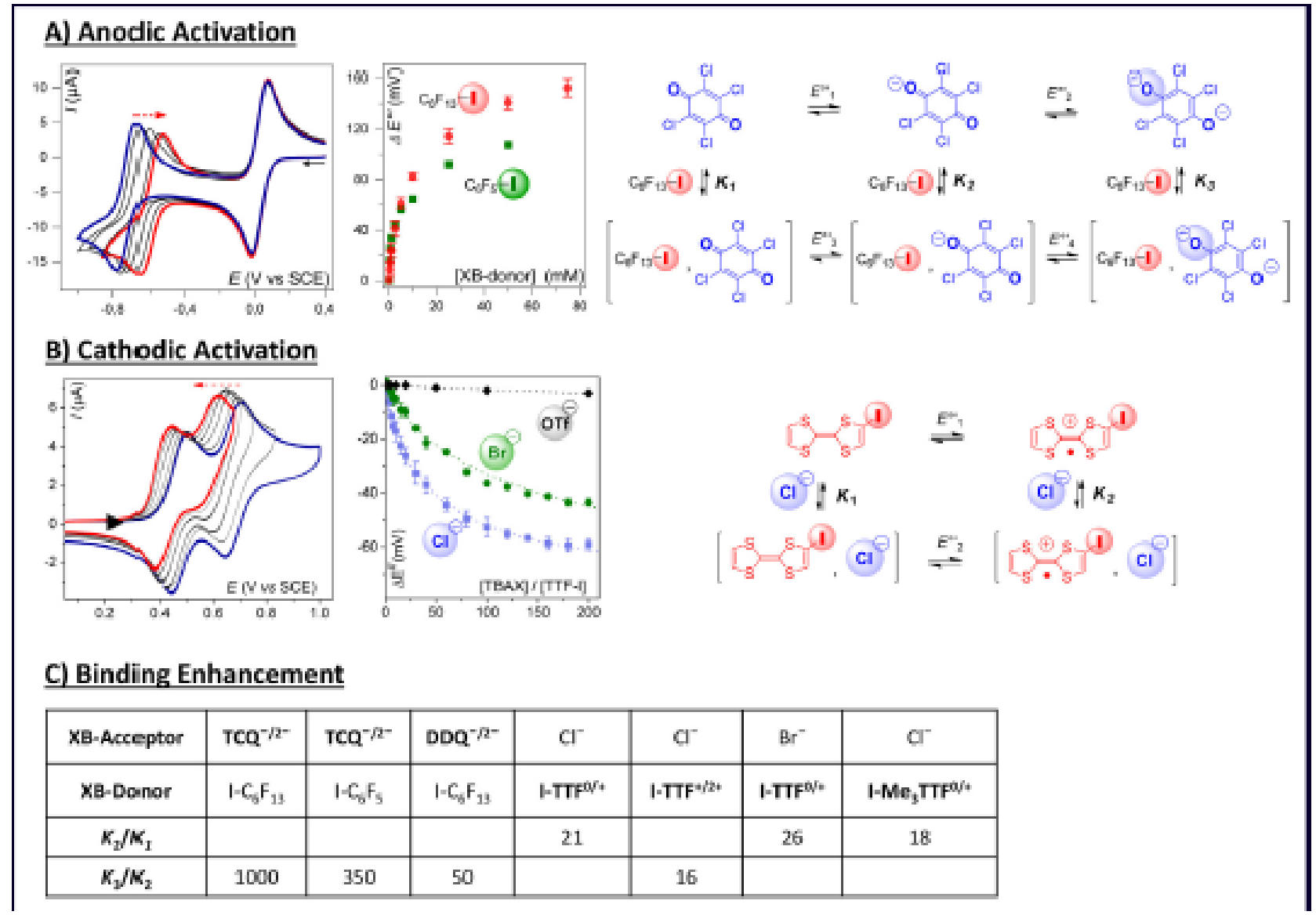

CVs were recorded on a glassy carbon electrode in a solution of $0.1 \mathrm{M} \mathrm{TBAPF}_{6}$ in acetonitrile at a scan rate $0.1 \mathrm{~V} \mathrm{~s}{ }^{-1}$. (a) CVs of TCQ (0.5 mM) in the presence of $\mathrm{IC}_{6} \mathrm{~F}_{13}(0,0.5,5,25$ and $50 \mathrm{mM})$; titration curves; corresponding Square Scheme. (b) CVs of I-TTF $(0.25 \mathrm{mM})$ in the presence of chloride (0, $0.25,1,2.5,5,10,25$, and $50 \mathrm{mM})$; titration curves; corresponding Square Scheme. (c) Table of affinity constant ratios $\left(\mathrm{K}_{\mathrm{i}+1} / \mathrm{K}_{\mathrm{i}}\right)$ for $\mathrm{XB}$-donor/XB-acceptor

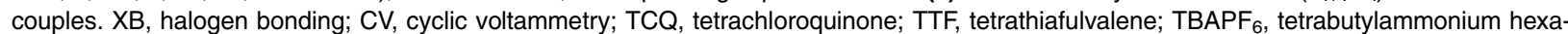
fluorophosphate; DDQ, dichlorodicyanoquinone; SCE, saturated calomel electrode; TBAX, tetrabutylammonium $X(X=$ anion).

in solution. Beer and colleagues have prepared several Fc derivatives bearing two iodo-triazoles or cationic iodo-triazolium units (Figure 2). Some of these bidentate $\mathrm{XB}$ donors showed interesting anion receptor properties, suggesting a significant contribution of $\mathrm{XB}$. In CV and square wave voltammetry (SWV) measurements, standard potential shifts of the ferrocenyl probes were observed in the presence of various anions, in particular halides (Fc-1, Figure 2) [31] and azide (Fc-2, Figure 2) [32]. In all cases, the respective affinity constants $\left(K_{\mathrm{a}}\right)$ of the iron (II) $(\mathrm{Fc})$ containing $\mathrm{XB}$ donors could be determined by ${ }^{1} \mathrm{H}$ NMR which was not possible for the activated paramagnetic iron (III) complexes (ferricinium). Thus, electrochemical techniques have not been used yet to quantify, via titration experiments and fitting to an appropriate model, the affinity constants for the activated receptors. However, when comparing the potential shift values of analogs $\mathrm{XB}$ (iodinated triazoliums) and $\mathrm{HB}$ receptors, $\mathrm{XB}$ proved to be equivalent or even stronger in the investigated liquid electrolytes. A tri-ferrocenylbis(iodotriazole) (Fc-3, Figure 2), conceived by the group of Molina, showed two reversible oxidation steps involving a two-electron and a one-electron transfer and proved to be remarkably selective toward oxoanions, affecting either the oxidation potential of the second ET (sulfate, acetate) or of both (dihydrogenophosphate and hydrogenopyrophosphate), whereas halides and nitrate showed no effect [33]. Electrochemical activation of $\mathrm{Fc}$-based $\mathrm{XB}$ donors could also be performed in up to $10 \%$ of watercontaining solvent mixtures [31]. Recently, a tetraiodinated monocationic [2]-Rotaxane bearing a ferrocenyl moiety as an interlocked host molecule showed weak perturbation of the voltammetric signal (in a acetone/acetonitrile/water mixture) but still selective recognition of bromide versus chloride or linear thiocyanate [34]. 


\section{Reductive XB deactivation}

$\mathrm{N}, \mathrm{N}^{\prime}$-disubstituted viologens constitute an important class of redox mediators widely applied in catalysis and the elaboration of supramolecular complexes [24]. Iodinated dicationic viologen derivatives were used as potent XB donors in the thermodynamically stable redox state. Reduction to the cation radical or the neutral state proved to significantly decrease the respective $\mathrm{XB}$-donor strength. Based on this principle, reversible reduction of a diquat bis-iodotriazole derivative (I-Diquat, Figure 2) was used for the electrochemical sensing of halide anions [35]. A comparative study of different noncovalent interactions between cationic N-phenylviologens and halides was performed (I-PV, Figure 2) [36]. XB contributed to a stabilization of the initially dicationic redox state of the iodo-tetrafluorophenyl viologen derivative in the presence of chloride and bromide, although the role of other competing noncovalent interactions ( $\mathrm{HB}$, ion pairing and $\pi$-anion interactions) is not fully understood. CV allowed the quantification of the overall affinity of halide anions toward N-phenylviologens depending on their redox state. Local probing of the various interactions was possible, thanks to NMR spectroscopy of the diamagnetic phenyl viologen dications.

\section{Interfacial redox switching of halogen bonding}

Noncovalent interactions play an important role in interfacial supramolecular electrochemistry [37]. Recently, the concept of electrochemical XB activation has been transferred onto the electrode surface via the immobilization of diiodinated TTF dithiolane derivatives in form of self-assembled monolayers (SAMs) on gold surface. Thus electrochemically driven interfacial charge-assisted halogen bonding between redoxactive SAMs and halide anions has been explored for the first time [38]. The XB-donor properties of the surface adsorbates $\left(\mathrm{I}_{2}\right.$-TTF, Figure $\left.4 \mathrm{~A}\right)$ were activated by electrochemical switching their oxidation state. A particularly high and selective binding enhancement of 565 (ratio of affinity constants for the two TTF oxidation states) upon oxidation of the SAM toward chloride anions was estimated from electrochemical simulation, suggesting a significant surface chelate effect of the assembled 2D material. Strong evidence is provided for a significant contribution of $\mathrm{XB}$ as the dominant noncovalent interaction in the investigated system. A high sensitivity (limit of detection $=6 \cdot 10^{-6} \mathrm{M}$ ) was determined for chloride detection which is a promising finding considering a potential application of the

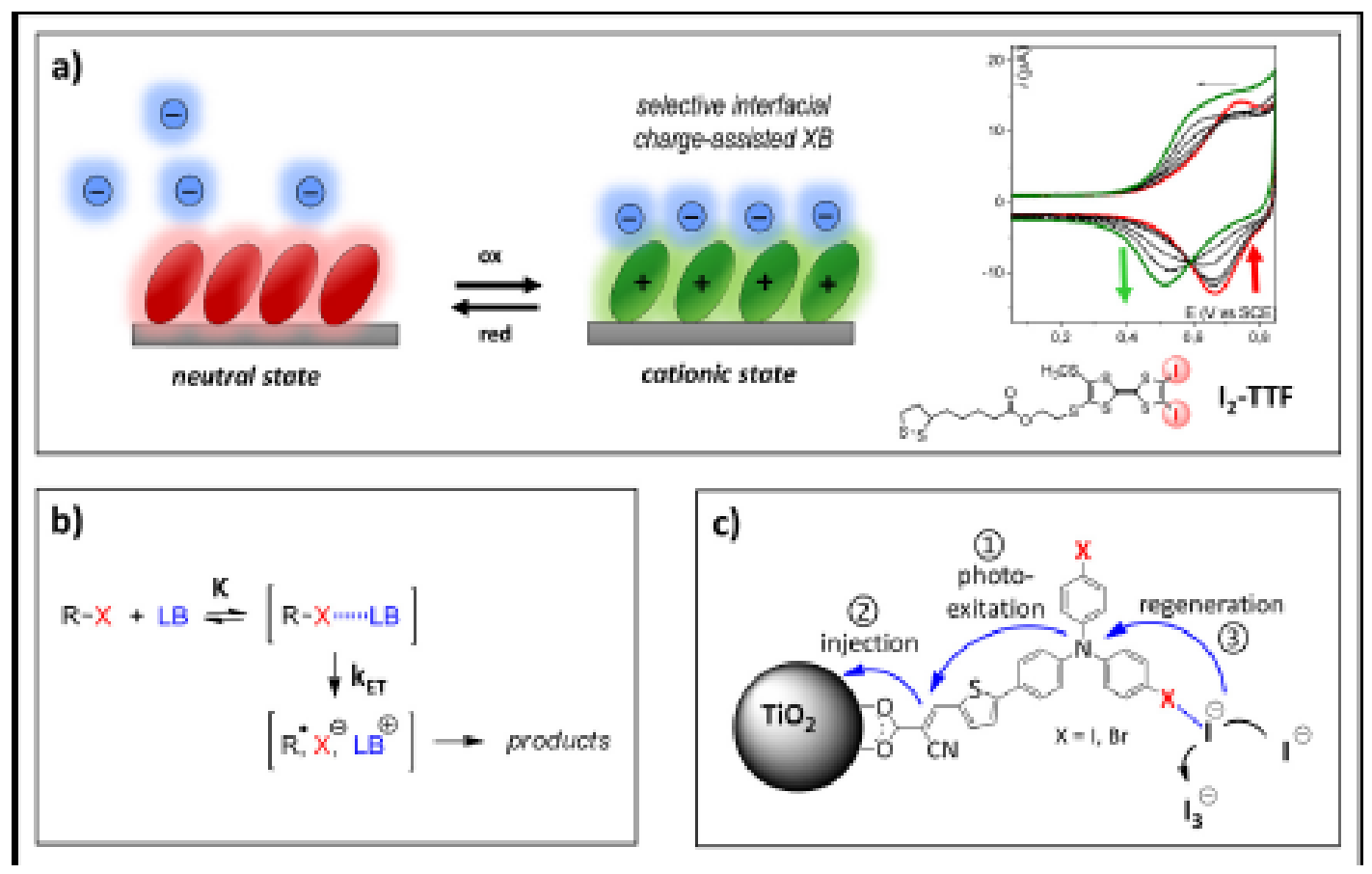

Interfacial redox switching and XB promoted electron transfer. (a) Scheme of selective interfacial anion detection on a SAM (left) and cyclic voltammograms of the electroactive $\mathrm{I}_{2}$-TTF containing SAM in the presence of increasing chloride concentrations (right). (b) Proposed mechanism for XB assisted EC between halocarbons (R-X) and a redox-active Lewis Base (LB). (c) Postulated mechanism of XB promoted regeneration of a photooxidized halogenated dye in a solar cell. SAM, self-assembled monolayer; $X B$, halogen bonding; TTF, tetrathiafulvalene; EC, electrochemical-chemical. 
concept for future development of novel selective anion sensors, capture/release systems, or molecular electronics.

\section{XB promoted ET reactions}

The group of Rosokha described halogen bond-assisted ETreactions of aliphatic bromo-substituted electrophiles $[39,40]$. The isolation of halogen-bonded prereactive complexes between aliphatic organobromides and Lewis bases (phenylene diamine and iodide) at low temperature and the kinetics of a subsequent ET are consistent with an inner-sphere mechanism involving strongly coupled redox centers (Figure 4B). Electronic coupling of $\mathrm{XB}$ donor and $\mathrm{XB}$ acceptor within the prereactive complex was suggested. Up to date, we are aware of only one example exploiting this potentiality for the regeneration of a photo-oxidized halogenated dye via iodide oxidation, thus impacting the open-circuit voltage of a solar cell (Figure 4C) [41]. Parlane et al [42] used X-ray absorption spectroscopy to directly detect interfacial XB between a homologous soluble halide species $\left(\mathrm{Cl}^{-}\right)$and the activated dye cation demonstrating that these interactions occur after electron injection into $\mathrm{TiO}_{2}$.

\section{Conclusions and perspectives}

Most of the work on the electrochemical investigation of $\mathrm{XB}$ has been published during the past 5 years, and many potentialities in this domain are still to be explored. However, the fundamental concept of electrochemical XB activation/deactivation for molecular recognition and detection is now well established. Several reversible redox probes have been used, covering the activation of $\mathrm{XB}$ donors (TTF, $\mathrm{Fc}$ ) and $\mathrm{XB}$ acceptors (quinones) as well as the deactivation of $\mathrm{XB}$ donors (viologen cations). Examples of electrochemical deactivation of $\mathrm{XB}$ acceptors for $\mathrm{XB}$ are not described yet. The possibility of reversible switching between three different redox states $(0 / \pm 1 / \pm 2)$ represents a decisive advantage for detecting a wide panel of analytes. It is noteworthy that besides some first conclusive results, there is still an important lack of spectroelectrochemical measurements.

Recognition of neutral Lewis bases [43], instead of anions, involving redox-active $\mathrm{XB}$ donors would also be an important and challenging issue. It is likely that the design of tailored oligo-dentate receptors will be required eventually benefitting from the cooperative interplay of multiple complementary noncovalent interactions. Another issue, already approached in some of the above cited examples, is the attempt to promote the high potential of $\mathrm{XB}$ to complement $\mathrm{HB}$ in the selective recognition and sensing of biologically and industrially relevant anions under aqueous conditions. Besides selective detection, also the specific capture/release of anions should be considered for biomedical applications in particular. The principle of redox switching of XB has been successfully transferred from solution onto an electrode surface. This approach opens the way for the development of new electrochemical sensors or sponge captors for depollution applications.

Finally, we believe that $\mathrm{XB}$ promoted ET reactions involving the activation of covalent bonds represents a completely new domain for exploration. Evidence for prereactive $\mathrm{XB}$ complexes in the dissociative reduction of C-X bonds involving an inner-sphere ETstep provides a new perspective on electrochemical reduction of organic halides in general [44]. At the same time, it seems to be a pivotal question paving the way, not only to a better mechanistic understanding of other halogen involving electrochemical-chemical (EC) or electrochemical-chemical-electrochemical (ECE) [45] mechanisms but also helping to identify new electrochemically assisted catalytic reactions. In the first encouraging example concerning solar cells, it has been shown challenging but possible to experimentally prove how weak XB interactions can affect interfacial ET reactions.

In conclusion, we strongly believe that $\mathrm{XB}$ should be considered as a powerful tool in molecular electrochemistry at a similar level as complementary HB. The stronger directionality of $\mathrm{XB}$ should be an important advantage for the conception of supramolecular systems and property prediction. Furthermore, future work in this domain should be accompanied more often by molecular modeling as a computational tool for confirming, optimizing and predicting structure/property relationships.

\section{Conflict of interest}

Nothing declared.

\section{Acknowledgements}

The authors gratefully acknowledge the financial support from the University Sorbonne Paris Cité (IDEX HalBond) and the Centre National de la Recherche Scientifique (CNRS).

\section{References}

Papers of particular interest, published within the period of review, have been highlighted as:

- of special interest

$\bullet$ of outstanding interest

1. Gilday LC, Robinson SW, Barendt TA, Langton MJ, Mullaney BR, Beer PD: Halogen bonding in supramolecular chemistry. Chem Rev 2015, 115:7118-7195.

2. Cavallo G, Metrangolo P, Milani R, Pilati T, Priimagi A, Resnati G,

- Terraneo G: The halogen bond. Chem Rev 2016, 116: 2478-2601.

Most recent review on all aspects of halogen bonding.

3. Desiraju GR, Ho PS, Kloo L, Legon AC, Marquardt R, Metrangolo P, Politzer P, Resnati G, Rissanen K: Definition of the halogen bond. Pure Appl Chem 2013, 85:1711-1713.

4. Fourmigué M: Halogen bonding: recent advances. Curr Opin Solid State Mater Sci 2009, 13:36-45. 
5. Meyer F, Dubois P: Halogen bonding at work: recent applications in synthetic chemistry and materials science. CrystEngComm 2013, 15:3058-3071.

6. Boubekeur K, Syssa-Magalé JL, Palvadeau P, Schöllhorn B: Selfassembly of nitroxide radicals via halogen bondingdirectional NO...I interactions. Tetrahedron Lett 2006, 47 $1249-1252$

7. Weingarth M, Raouafi N, Jouvelet B, Duma L, Bodenhausen $G$, Boujlel K, Schöllhorn B, Tekely P: Revealing molecular selfassembly and geometry of non-covalent halogen bonding by solid-state NMR spectroscopy. Chem Commun 2008, 45 $5981-5983$

8. Syssa-Magalé JL, Boubekeur K, Leroy J, Chamoreau LM, Fave C, Schöllhorn B: Directed synthesis of a halogen-bonded open porphyrin network. CrystEngComm 2014, 16: $10380-10384$.

9. Lieffrig J, Jeannin O, Fraxckowiak A, Olejniczak I, Świetlik R, Dahaoui S, Aubert E, Espinosa E, Auban-Senzier P. Fourmigué M: Charge-assisted halogen bonding: donor-acceptor complexes with variable ionicity. Chem Eur J 2013, 19:14804-14813.

10. Erdélyi M: Halogen bonding in solution. Chem Soc Rev 2012, $41: 3547-3557$

11. Beale TM, Chudzinski MG, Sarwar MG, Taylor MS: Halogen bonding in solution: thermodynamics and applications. Chem Soc Rev 2013, 42:1667-1680.

12. Jentzsch AV: Applications of halogen bonding in solution. Pure Appl Chem 2015, 87:15-41.

13. Dumas JM, Gomel M, Guerin M: Molecular interactions involving organic halides. In Halides, pseudo-halides and azides, vol. 2. Chichester, U.K.: John Wiley \& Sons, Ltd.; 1983:985-1020.

14. Groni S, Maby-Raud T, Fave C, Branca M, Schöllhorn B:

-. Electrochemical controlling and monitoring of halogen bond formation in solution. Chem Commun 2014, 50: $14616-14619$.

First example and proof of principle for electrochemical activation of halogen bonding in solution. Redox-switching of an XB-acceptor in the presence of $\mathrm{XB}$ and $\mathrm{HB}$ donors. The following aspects are treated: binding enhancement, reversibility, stoichiometry of the $\mathrm{XB}$ complex selectivity, XB-acceptor competition.

15. Chambers JQ [chapter 14]. Patai S, Rappoport Z. The chemistry of the quinoid compounds, vol. 1. New York: Wiley; 1974: 737-791. 1988, [chapter 12], vol. 2, pp. 719-757.

16. Lund H, Baizer MM: Organic electrochemistry. 3rd ed. New York: Marcel Dekker; 1991

17. Smith DK: Electrochemically controlled hydrogen bonding for supramolecular assembly: challenges and opportunities. Curr Opin Electrochem 2017, 2:76-81.

18. Katsumi J, Nakayama T, Esaka Y, Uno B: Mechanistic study on the electrochemical reduction of 9,10-anthraquinone in the presence of hydrogen-bond and proton donating additives. Anal Sci 2012, 28:257-265.

19. Hui Y, Chng ELK, Chng CYL, Poh HL, Webster RD: Hydrogen-bonding interactions between water and the oneand two-electron-reduced forms of vitamin K1: applying quinone electrochemistry to determine the moisture content of non-aqueous solvents. J Am Chem Soc 2009, 131: $1523-1534$

20. Shi RRS, Tessensohn ME, Lauw SJL, Fooa NABY, Webster RD: Tuning the reduction potential of quinones by controlling the effects of hydrogen bonding, protonation and proton-coupled electron transfer reactions. Chem Commun 2019, https:// doi.org/10.1039/c8cc09188a.

21. Constentin C: Electrochemical approach to the mechanistic study of proton-coupled electron transfer. Chem Rev 2008, 108:2145-2179.

22. Philip Jr RH, Layoff T, Adams RN: The effect of lithium ion on the mechanism of the polarographic reduction of benzil in dimethylformamide. J Electrochem Soc 1964, 111:1189-1190.
23. Desbene-Monvernay A, Lacaze PC, Dubois JE, Cherigui A: Ionpair effects on the electroreduction and electrochromic properties of ortho-chloranil in dipolar aprotic solvents. J Electroanal Chem Interfacial Electrochem 1987, 216:203-212.

24. Beer PD, Langton MJ: Anion, cation and ion-pair recognition by macrocyclic and interlocked host systems. In Izatt Reed M vol. 3; 2016:38-71.

25. Gale PA, Caltagirone C: Anion sensing by small molecules and molecular ensembles. Chem Soc Rev 2015, 44: $4212-4227$.

26. Schulze B, Schubert US: Beyond click chemistry - supramolecular interactions of 1,2,3-triazoles. Chem Soc Rev 2014, 43 2522-2571.

27. Dreger A, Engelage E, Mallick B, Beer PD, Huber SM: The role of charge in 1,2,3-triazol(ium)-based halogen bonding activators. Chem Commun 2018, 54:4013-4016.

28. Fourmigué M, Batail P: Activation of hydrogen- and halogenbonding interactions in tetrathiafulvalene-based crystalline molecular conductors. Chem Rev 2004, 104:5379-5418.

29. Oliveira R, Groni S, Fave C, Branca M, Mavré F, Lorcy D,

-• Fourmigué M, Schöllhorn B: Electrochemical activation of a tetrathiafulvalene halogen bond donor in solution. Phys Chem Chem Phys 2016, 18:15867-15873.

First and thorough study of the redox-switching of a mono-dentate (TTF based) XB-donor involving 3 oxidation states in polar electrolytes quantifying binding constants/enhancement, selectivity, XB- and HBdonor competition, polar and protic electrolyte solvents.

30. Oliveira R, Groni S, Vacher A, Barrière F, Lorcy D,

- Fourmigué M, Maisonhaute E, Schöllhorn B, Fave C: Electrochemical activation of TTF-based halogen bond donors: a powerful, selective and sensitive analytical tool for probing a weak interaction in complex media. Chemistry 2018, 3: 8874-8880.

Supplementary proof and systematic study of various parameters and methods influencing the electrochemical activation of iodinated TTF XB-donors treating also the following aspects: supporting electrolyte effects, spectro-electrochemistry, microelectrodes, XB/HB competition.

31. Lim JYC, Cunningham MJ, Davis JJ, Beer PD: Halogen

-• bonding-enhanced electrochemical halide anion sensing by redox-active ferrocene receptors. Chem Commun 2015, 51: $14640-14643$

First electrochemical activation of a bidentate XB-donor for the detection of halides. Affinity constants of the initial oxidation state are determined by NMR and shift values of the measured ferrocene oxidation potentials are suggesting binding enhancement due to $\mathrm{XB}$ formation.

32. Lim JYC, Beer PD: A halogen bonding 1,3-disubstituted

-• ferrocene receptor for recognition and redox sensing of azide. Eur J Inorg Chem 2017:220-224.

Host-guest shape and size complementarity of a novel bidentate XB receptor accounts for the selective electrochemical detection of azide over a range of anions with differing geometries.

33. Zapata F, Caballero A, Molina P. Ferrocene-triazole combination as a benchmark for the electrochemical detection of noncovalent halogen-bonding interactions. Eur J Inorg Chem 2017:237-241.

34. Lim JYC, Beer PD: Electrochemical bromide sensing with a

- halogen bonding [2]Rotaxane. Eur J Org Chem 2018, https:// doi.org/10.1002/ejoc.201801571.

This article reports on an original redox active tetradentate XB-donor.

35. Mullaney BR, Cunningham MJ, Davis JJ, Beer PD: Acyclic

- halogen and hydrogen bonding diquat-containing receptors for the electrochemical sensing of anions. Polyhedron 2016, 116:20-25.

First example for cathodic deactivation of $\mathrm{XB}$. The affinity constants of the dicationic bidentate $\mathrm{XB}$-donors towards anions were determined by NMR spectroscopy.

36. Creste G, Groni S, Fave C, Branca M, Schöllhorn B: Compara-

-• tive study of non-covalent interactions between cationic Nphenylviologens and halides by electrochemistry and NMR: the halogen bonding effect. Faraday Discuss 2017, 203: 301-313. 
A series of different halo-phenyl viologens has been studied by cyclic voltammetry and NMR spectroscopy analyzing the competition of the involved non-covalent interactions (XB, HB and $\pi$-anion).

37. Cui K, Dorner I, Mertens SFL: Interfacial supramolecular electrochemistry. Curr Opin Electrochem 2018, 8:156-163.

38. Hijazi H, Vacher A, Groni S, Lorcy D, Levillain E, Fave C,

-• Schöllhorn B: Electrochemically driven interfacial halogen bonding on self-assembled monolayers for anion detection. Chem Commun 2019, 55:1983-1986.

The concept of reversible redox switching XB for molecular anion recognition and detection has been successfully transferred from solution onto an electrode surface.

39. Rosokha SV, Vinakos MK: Halogen bond-assisted electron

-• transfer reactions of aliphatic bromosubstituted electrophiles. Phys Chem Chem Phys 2014, 16:1809-1813.

Evidence for pre-reactive XB complexes in the dissociative reduction of $\mathrm{C}-\mathrm{X}$ bonds involving an inner-sphere ET step provides a new perspective on electrochemical reduction of organic halides.

40. Rosokha SV: Electron-transfer reactions of halogenated

-• electrophiles: a different look into the nature of halogen bonding. Faraday Discuss 2017, 203:315-332.

This article analyses kinetic data confirming a decrease of the ET barrier between halogen-bonded reactants suggesting that halogen bonding should be considered in reaction mechanisms of halogenated species.

41. Swords WB, Simon SJC, Parlane FGL, Dean RK, Kellett CW, Hu K, Meyer GJ, Berlinguette CP: Evidence for interfacial halogen bonding. Angew Chem Int Ed 2016, 55:5956-5960.

42. Parlane FGL, Mustoe C, Kellett CW, Simon SJ, Swords WB

-• Meyer GJ, Kennepohl P, Berlinguette CP: Spectroscopic detection of halogen bonding resolves dye regeneration in the dye-sensitized solar cell. Nat Commun 2017, 8:1-8.

Direct evidence for halogen bonding at the dye-electrolyte interface using X-ray absorption spectroscopy suggesting that weak intermolecular interactions between photo-oxidized dyes and the electrolyte can impact device photovoltages.

43. Laurence C, Graton J, Berthelot M, El Ghomari MJ: The diiodine basicity scale: toward a general halogen-bond basicity scale. Chem Eur J 2011, 17:10431-10444.

44. Savéant JM: Elements of molecular and biomolecular electrochemistry. An electrochemical approach to electron transfer chemistry. John Wiley; 2006.

45. Bard AJ, Faulkner LR: Electrochemical methods - fundamental applications. chapter II - electrode reactions with coupled homogeneous chemical reactions. 2nd ed. John Wiley; 2001:429. 